\title{
Migraçóes sob o esquadro e o compasso: 300 anos de histórias da maçonaria
}

\author{
Migrations under the Square and Compasses: 300 Years of Freemasonry Stories \\ Migraciones bajo la escuadra y el compás: 300 años de historias de la masonería
}

\section{Felipe Corte Real de Camargo ${ }^{1 *}$}

ESQUIVEL, Ricardo Martínez; ANDRÉS, Yvan Ponzuelo; ARAGÓN, Rogelio (Org.). 300 años: Masonerías y Masones (17172017). Tomo I: Migraciones. Ciudad de México: Palabra de Clío, 2017. 194p.

Escrever uma antologia é sempre uma tarefa complexa. Mais do que a reuniáo de textos diversos sobre um determinado assunto, é necessário ritmo, coerência e coesão; além de unidade temática e estilística, mesmo para textos contraditórios entre si. Tal necessidade aumenta ao se produzir uma antologia em cinco volumes, da qual o primeiro volume é o tema aqui.

A coleção 300 Años de Masonería (Esquivel, 2017) busca organizar as ideias e os ideais, que bem poderíamos chamar de pós-coloniais, que vêm sendo produzidos em torno da Revista de Estudios Historicos de la Masonería Latinoamericana y Caribeña (REHMLAC). Com dez anos de existência, o periódico ascendeu de um difusor dos trabalhos latinos sobre história da maçonaria para um coletivo de ideias que, por exemplo, organizou sua própria (e maior) mesa no úl- timo Congresso Mundial sobre Fraternalismo, Maçonaria e História, em Paris. ${ }^{1}$ Mesa esta que avivou o debate sobre a pluralidade da maçonaria em suas práticas e seus pensamentos reafirmando que náo deve haver maçonaria no singular para quem pesquisa este fenômeno.

Os editores da coleção, Ricardo Martínez Esquivel, Yvan Ponzuelo Andrés e Rogelio Aragón - respectivamente diretor, editor e contribuidor regular da REHMLAC -, segundo suas falas nos congressos de Paris (maio de 2017) e Havana ${ }^{2}$ (julho de 2017), querem demonstrar o caráter plural do fenômeno maçônico, ou seja, das maçonarias. Por meio dessa multiplicidade querem também dar visibilidade à miríade de pesquisas e pesquisadores que a Ordem ${ }^{3}$ abarca.

$\mathrm{O}$ primeiro volume tem o abrangente título Migraciones, desta maneira busca evidenciar os usos, as recepçóes e as apro-

\footnotetext{
${ }_{1}$ Painel: "Imperialism, Colonialism and Multiple Freemasonries". World Conference on Fraternalism, Free Masonry and History. 2017, Paris.

$2 \mathrm{~V}$ Simposio Internacional de la Masonería Latinoamericana y Caribeña. 2017, La Habana.

3 São termos intercambiáveis: Maçonaria, Franco-Maçonaria, a Ordem, a Fraternidade, entre outros.
}

DOI: http://dx.doi.org/10.1590/2237-101X01903812

Resenha recebida em 4 de setembro de 2017 e aprovada para a publicação em 11 de outubro de 2017.

${ }^{1}$ Universidade de Bristol, Bristol, Reino Unido.

* Doutorando pela Universidade de Bristol, Inglaterra. E-mail: fc15629@bristol.ac.uk. 
priações não somente do fenômeno estruturante que é a maçonaria, como os impactos produzidos pelo que poderíamos chamar de “ideário maçônico", que se confunde - mesmo por ser produtor e produto - com a própria modernidade.

$\mathrm{Na}$ primeira parte do livro, tal como na tradição universitária, temos a fala do decano. $\mathrm{O}$ professor dr. José Ferrer Benimeli, com mais de 40 anos de pesquisas em torno do tema, revisa as fontes e a historiografia produzida entre Espanha e México no oitocentos. Assim, demonstra os usos feitos da história da maçonaria, tanto nas vertentes laudatórias quanto nas detratórias. Desta maneira póe em xeque meias-verdades e mitos perpetuados por historiadores profissionais e amadores, com as intenções mais diversas. Apresentando erudição não somente da história da maçonaria como da história do mundo ibérico, Benimeli demonstra a relevência dos estudos maçônicos e suas ligações não somente aos temas mais variados da historiografia tradicional, mas também sua utilidade para problematizar questóes propostas e por vezes tidas por resolvidas. Porém, o desfile erudito de autores, fatos, fontes e datas se apresenta pouco convidativo para o "abre-alas" de uma antologia. No afã de clarificar uma discussão nebulosa, Benimeli demonstra de maneira crua que para desvendar o hermetismo da história da maçonaria é necessário adentrar dois outros: o da historiografia e o da diplomática.

O capítulo seguinte segue uma metodologia semelhante, a divisão da argumentação em três tempos, e fica a cargo de um dos mais renomados professores da Universidade de La Habana (Cuba), Eduardo Torres-Cuevas. $\mathrm{O}$ historiador nos leva pela fragmentada história da maçonaria cubana por meio de suas divisóes e influências. Ao ler o segundo capítulo, o leitor percebe que há um certo padrão fragmentário nas maçonarias latinoamericanas e que tais cisóes acontecem por dois motivos principais: as variadas influências recebidas (Espanha, França, Inglaterra e Estados Unidos) e o papel central que as organizaçóes maçônicas ou criadas nos moldes da maçonaria irão execer nas nascentes repúblicas. Tal atuação se deve ao fato de que as lojas maçônicas se apresentam como os primeiros corpos de auto-organização político-partidária nos séculos XVIII e XIX na América Latina.

Torres-Cuevas coloca em suspenso questôes sobre as origens da maçonaria na ilha. Seguindo também a tradição mais clássica, tal como Benimeli, prende suas conclusões a provas documentais. Porém, insinua bastante livremente sobre possibilidades, chegando inclusive a apontar uma possível presença de "maçons operativos" (pedreiros que teriam sido a origem da maçonaria moderna, dita "especulativa”) na construção da Catedral de Havana. Das primeiras lojas fundadas no final do século XVIII por maçons fugidos da Revolução Haitiana, passando pela profusão de lojas e Grandes Orientes por quase 30 anos até o período final do século XIX, no qual se estabelecem as potências maçônicas que formariam o panorama da Ordem em Cuba no século XX, o autor oferece uma história bem costurada com pausas para análises bastante sintéticas, auxiliando o entendimento de uma história com muitas 
nuances e recheada de jargóes.

O capítulo de Éric Saunier, professor da Universidade do Havre (França) demonstra, por meio de uma escrita fluida e precisa, como a história da maçonaria compóe um mosaico com a história política. Por meio de uma problemática que muito bem poderia se resumir a questiúnculas relativas a lojas maçônicas periféricas e suas relações com a sua obedicência central, Saunier apresenta de que modo se deram costuras políticas que permitiram lojas maçonicas antilhanas e lojas maçônicas francesas em cidades portuárias a continuarem fiéis às políticas poligenistas, impedindo a iniciação de negros em suas lojas, contrariando assim a política liberal parisiense do Grande Oriente da França. O capítulo de Saunier reflete a teoria que mesmo dentro de uma mesma obediência maçônica há variados entendimentos sobre sua práxis, cessando, uma vez mais, o entendimento ingênuo da maçonaria como homogênea e unívoca.

Ricardo Martinez Esquivel assina o capítulo que trata $\mathrm{da}$ origem da maçonaria centro-americana, nascida em seu país, Costa Rica. O autor discorre com desenvoltura sobre o tema, sobre o qual pesquisa há quase dez anos, principalmente quando foca na análise das redes de sociabilidade que a fraternidade teceu naquele país e nos seus vizinhos, ano após ano. $\mathrm{O}$ ponto forte do artigo se apresenta na relação que Esquivel estabelece entre os dados de suas pesquisas prévias com panoramas mais gerais da história da chamada América Latina. Mesmo o leitor neófito no tema poderá entender o peso que a francomaçonaria teve a partir da segunda metade do século XIX e os motivos para as rusgas entre a Igreja Católica e seus membros. Pretendendo apresentar um panorama muito completo, o artigo de Esquivel tende, a partir da metade do texto, para uma narrativa mais tradicional da história política, o que contrasta fortemente com a primeira parte, mais analítica e arrojada.

$\mathrm{Na}$ sequência, os primeiros anos da maçonaria mexicana são passados em revista pela experiente historiadora Maria Eugênia Vazques Samenedi. Com consistente trajetória acadêmica no campo da história da maçonaria, a autora revisa as obras que (por antiguidade ou merecimento) são tidas como indispensáveis para contar a história da Fraternidade em território mexicano. Mesclando análise, crítica e novas fontes, a historiadora desmonta mitos maçônicos mexicanos, como a "lenda" de que a primeira loja maçônica no México dataria de 1806 e que se localizaria na Calle de las Ratas. Além deste, desmonta o argumento, bastante comum, entre os historiadores mais tradicionais, de que a fundação das lojas maçônicas teria um caráter eminentemente político. Somente por esses dois feitos, o capítulo já se torna indispensável para qualquer pesquisador do tema na América Latina. Porém, mais do que isso, a historiadora aclara, de maneira sutil, nas últimas páginas, algumas questóes de teoria e metodologia que tendem a ser negligenciadas em temas que não fazem parte do mainstream historiográfico, como a diferenciação entre a análise da história de uma instituição e a análise das narrativas que se fazem sobre ela.

Dévrig Mollès, historiador e diretor cien- 
tífico do Arquivo da Grande Loja da Argentina, traz um olhar desde aquele país sobre a chegada do feminismo na América Latina. Com esse tema demonstra o papel central que a maçonaria teve ao servir como base, dada sua capilaridade, aos movimentos vanguardistas do começo do século (feminismo, anticlericalismo, livre-pensamento) que configuraram o moderno sistema-mundo. Tal fenômeno teria ocorrido dado que as redes maçônicas formaram uma "plataforma de transferências culturais e um espaço de lutas culturais". A escrita de Mollès flui de maneira singular, sua clareza conceitual e suas escolhas bibliográficas, enxutas e certeiras, fazem de seu capítulo um ótimo panorama sobre os movimentos de emancipação feminina na América Latina, suas relaçôes com os movimentos socialistas e com a maçonaria.

$\mathrm{O}$ historiador chileno Felipe Santiago del Solar nos oferece um breve panorama dos primeiros anos da maçonaria no Chile. Para tal, faz uma análise das primeiras obras que dão conta das atividades maçônicas no país andino. Este recorrido, del Solar não o faz apenas por uma questão de crítica historiográfica, mas porque a grande maioria da documentação maçônica chilena se perdeu após um terremoto no começo do século XX. Apesar de bastante conciso, o capítulo é o relato de uma trajetória maçônica bastante tardia e singular se comparada aos outros países latinos.

O fechamento do livro fica nas mãos de Guillermo de los Reyes-Heredia, professor da Universidade de Houston (Estados Unidos), que escreve sobre um tema que pode não parecer "demasiado maçônico", à primeira vista.
A sociedade civil, seus elementos e constructos são analisados de maneira bastante didática pelo autor, que busca entender de que maneira as organizaçóes voluntárias têm o poder de promover, criar e contribuir para a democracia (e se, de fato, contribuem). Analisando a maçonaria nesse espectro teórico mais amplo o autor clarifica uma das discussóes mais recorrentes - porém pouco aprofundadas - no campo da história da maçonaria na contemporaneidade: aquela relativa à esfera pública. O debate, trazido atualmente por Habermas, é tema obrigatório em todo trabalho sobre a Franco-Maçonaria, e este capítulo é um bom guia para aqueles que desejam abordar o tema com maior propriedade. Além do cabedal teórico, em sua maioria oriundo da Ciência Política, apresentado pelo autor, somos também brindados com uma pequena análise da mitologia maçônica em sua expressão estadunidense, e de como a exacerbação, ou mero exagero, do papel da maçonaria na história política dos países se expressa em um aumento de importância real da Ordem.

A crítica a este volume é a mesma que se pode fazer a qualquer compilação de ensaios sobre a maçonaria, isto é, os autores estão separados por um tema comum. Explico: como a maçonaria foi, e continua sendo, um tema marginal na academia, há uma considerável defasagem teórica, muitas vezes causada pela necessidade dos autores acadêmicos de se comunicar com o seu público, mormente leigo, no que concerne às questôes historiográficas. Outro traço dessa separação é a variedade de termos para definir as questóes maçônicas que por vezes tais pesquisadores cunham e aplicam unilateralmente. Variedade esta causada 
pela falta de conhecimento dos termos usados pelos próprios maçons ou, quando há o conhecimento destes, devido a uma necessidade de se diferenciar dos "maçons historiadores". A história da maçonaria tem sido produzida por maçons frequentemente sem formação acadêmica na área das humanidades, o que torna fundamental a crítica à produção "domingueira”. Seja qualquer um dos motivos, a falta de uniformidade conceitual pode inquietar quem conhece os termos maçônicos e confundir quem deseja conhecer.

De qualquer maneira, o primeiro volume desta coleção mostra que os estudos acerca da maçonaria evoluem para um debate mais público e qualificado. Longe de ser uma seita ou uma religiáo, ou ainda uma conspiração para dominar o mundo, conforme as crendices à direita e à esquerda, a maçonaria é um capítulo incontornável da história moderna e contemporânea. Como todos os mitos da modernidade, urge desativá-la na sua mística e analisá-la em sua historicidade. Para quem deseja dar os primeiros passos ou incrementar os que já foram dados, Migraciones será uma grata surpresa.

\section{Como citar:}

ESQUIVEL, Ricardo Martínez; ANDRÉS, Yvan Ponzuelo; ARAGÓN, Rogelio (Org.). 300 años: masonerías y masones (1717-2017). Tomo I: Migraciones. Ciudad de México: Palabra de Clío, 2017. 194p. Resenha de CAMARGO, Felipe Corte Real de. Migraçôes sob o esquadro e o compasso: 300 anos de histórias da maçonaria. Topoi. Revista de História, Rio de Janeiro, v. 19, n. 38, p. 268-272, mai./ago. 2018. Disponível em: <www.revistatopoi.org $>$.

\section{Referência Bibliográfica}

ESQUIVEL, Ricardo Martínez; ANDRÉS, Yvan Ponzuelo; ARAGÓN, Rogelio (Org.). 300 años: Masonerías y Masones (1717-2017). Tomo I: Migraciones. Ciudad de México: Palabra de Clío, 2017. 194p. 